\title{
Mate Choice and Copulation Frequency in the Burying Beetle Nicrophorus quadripunctatus (Coleoptera: Silphidae): Effect of Male Body Size and Presence of a Rival
}

\author{
Seizi Suzuki \\ Center for e-Learning Research and Application, Nagaoka University of Technology, 1603-1 Kamitomioka, \\ Nagaoka, Niigata 940-2188, Japan \\ Correspondence should be addressed to Seizi Suzuki, seizi@oberon.nagaokaut.ac.jp
}

Received 30 April 2008; Revised 29 August 2008; Accepted 19 November 2008

Recommended by James Traniello

\begin{abstract}
It is widely assumed that there exists a competition between males for mating and that females prefer males with elaborate male traits. Further, such traits are considered to be synonymous with high quality in terms of benefits to females. The number and duration of copulations and the frequency of mate refusal between large and small Nicrophorus quadripunctatus males were examined both for single males and for two males competing. The number of copulations was not affected by the size of the male or by the presence of a rival, but there was a significant interaction such that large males increased their number of copulations when a small rival was present. Copulation duration was not affected by male size but was shortened by a rival male. Females rejected copulation attempts of small males more often than of large males, whether the males were alone or paired with a rival. These results suggest that large males have two advantages: they win contests between males and are preferred by females.
\end{abstract}

Copyright (C) 2009 Seizi Suzuki. This is an open access article distributed under the Creative Commons Attribution License, which permits unrestricted use, distribution, and reproduction in any medium, provided the original work is properly cited.

\section{Introduction}

Species which provide biparental care often exhibit monogamous mating behaviors since assistance from the male is essential for successful breeding [1]. Monogamous males fertilize most of the brood, but extrapair fertilizations (EPFs) have been observed in various species [2]. Since EPFs decrease the fitness of male partners, the frequency and/or influence of EPFs is reduced by male partners. Thus, male partners react to EPFs by guarding their mates and frequent copulations [3]. In contrast, females prefer males with some specific traits because fertilization with high-quality males brings about direct and/or indirect benefits [4]. Thus, the success of EPFs depends on both the competition between males and the mate preferences by the female; however, the interaction between these factors is poorly understood.

The complex parental behavior of burying beetles (Silphidae: Nicrophorinae: Nicrophorus) has been well studied (reviewed in [5, 6]). Nicrophorus exploits small vertebrate carrions as food for its young. Typically, a male-female pair prepares a carcass by burying, removing hair, and rounding it into a ball [7]. Eggs are laid in the soil adjacent to the carrion ball. After hatching, the larvae crawl to the carrion ball, where they are fed by parental regurgitations.

Nicrophorus is generally monogamous [8-11] and displays intense intrasexual competition in both sexes $[12,13]$. More than one individual of both sexes often locates a carcass, and usually a single, dominant male-female pair occupies the carcass. Both the males and females defend their carcass and brood even after the larvae hatch by attacking the intruders cooperatively [14-17]. Inferior individuals are occasionally present around the carcass as satellite males [18] and brood parasites [19]. Larger individuals usually win the contest among conspecifics $[12,20]$. Because females occasionally reject copulation with males [21], we hypothesize that females prefer to copulate with larger males and that they reject copulation with smaller males. In this study, we examined the number and duration of copulation and the frequency of mate refusal in N. quadripunctatus. In addition, we also examined the differences in the frequency of copulations in the presence and absence of other males. 


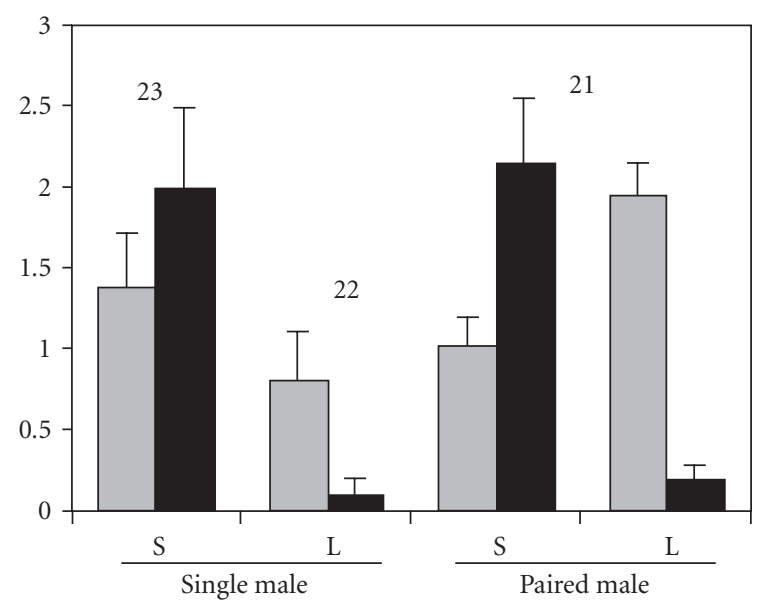

FIGURE 1: Number of copulation attempts (grey bar) and copulation rejections (black bar) for each treatment (mean \pm SE). Sample size of the observed copulations is shown at the upper part of each bar.

\section{Materials and Methods}

All beetles were caught in the field using hanging traps baited with rotten meat. For the experiments, N. quadripunctatus individuals were sorted into large- (pronotal width > $5.5 \mathrm{~mm})$, medium-(5.5 > pronotal width $>4.5 \mathrm{~mm})$, or small- $(<4.5 \mathrm{~mm})$ sized classes. The beetles were placed along with a small piece of chicken meat (approx. $15 \mathrm{~g}$ ) in a plastic arena $(50 \times 250 \times 50 \mathrm{~mm})$. The arenas were maintained under standard laboratory conditions of light and ambient temperatures. The treatments were as follows.

Treatment 1. A large or small male and a medium female were introduced into the arena (large: $N=22$, small: $N=23)$.

Treatment 2. A medium female and 2 males (a large and a small male) were introduced into the arena $(N=21)$.

The following behavioral interactions between the sexes were recorded for 1 hour. A copulation attempt was recorded when a male attempted to mount the female, and copulation success was recorded when a male mounted the female and successfully inserted his aedeagus. Using a stop-watch, the copulation duration was recorded from the time when the male beetle inserted his aedeagus to the time when he ceased mounting.

\section{Results}

The frequency of copulation between large and small males was not significantly different $(F=0.42, P=.52)$. In contrast, significant interaction between male size and the presence of rivals suggests that large males repeatedly copulated in the presence of small males than that of a single large male $(F=8.29, P<.01$, d.f. $=1$, two-way ANOVA, Figure 1). The copulation duration of single males was longer significantly than pair males $(F=6.57, P<.01$, d.f. $=1$, ANOVA, Figure 2).

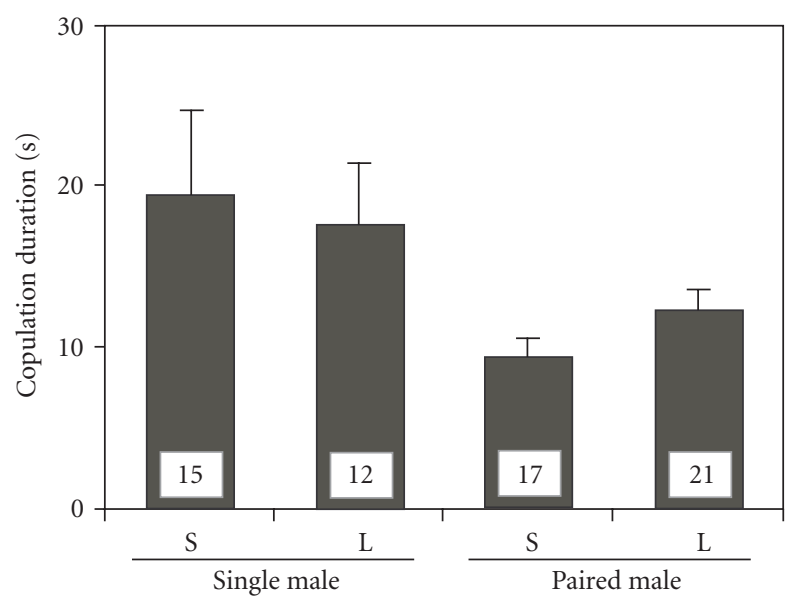

Figure 2: (Mean \pm SE) copulation duration for each treatment. Sample size of the observed copulations is shown at the base of each bar.

The females displayed two rejection behaviors: holding the abdomen down and moving away from the male [22]. The females tended to accept large males and reject the small males $(F=36.28, P<.01$, d.f. $=1)$, regardless of the presence of rival males $(F=0.28, P=.59$, d.f. $=1$, two-way ANOVA, Figure 1).

\section{Discussion}

Often two or more male burying beetles are found near a carcass [21]. Thus, intense competition between males has been reported $[12,13,23]$. The dominant male achieves higher paternity, but inferior males often stay around the carcass and copulate in $N$. vespilloides $[18,19]$.

Mate rejection is reported in N. vespilloides [22], but the reason for rejection is still unknown. This study revealed that females accepted larger males but rejected smaller males. In burying beetles, conspecific dominant-subordinate relationships are determined by the body size, and larger individuals usually win contests both between males and females [12]. However, even in the presence of only one male, the females prefer larger males over smaller ones as evidenced by the probability of copulation rejection. Thus, the outcome of the contest itself does not affect mate preferences. Since females often equate superior fighting ability with high quality in terms of fitness [24], they are generally attracted to dominant males in many animal species [25], except for a few (e.g., females of Pacific blue-eye fish do not use traits correlated with fighting ability to choose males [26]). The result of $N$. quadripunctatus coincides with the assumption that females generally prefer dominant males. Females maximize reproductive success by optimizing the "quality" of their mating partners [27], they are assumed to benefit by mating with dominant males.

In male burying beetles, our study revealed that the dominant males copulated more frequently in the presence of inferior males. Territorial (larger) males repeatedly copulated in the presence of other males (Figure 1). Dominant 
males of $N$. vespilloides require large number of repeated copulations to achieve sperm replacement for high paternity [18]. The act of repeated copulation was reported only for sperm displacement, and smaller males did not reduce their frequency of copulation in the presence of larger males (Figure 1). The territorial males have the method only with repeated copulations to prevent EPFs in N. vespilloides [18, 28]. Territorial males sire a much larger proportion of the brood $(60-100 \%,[18,19,29])$, and repeated copulations can largely prevent EPFs. In contrast, smaller males are at a disadvantage with regard to fertilization because their possibility of winning contests is low and their rejection as mates is high. Smaller males face a higher possibility of mate rejection, but the number of successful copulations by smaller males is not different from that by larger males without rival males. This demonstrated that smaller males attempted to copulate more frequently than larger males; this also suggested that the smaller males acquired more EPFs by repeated copulation attempts.

It is often stated that males that win contests are the preferred mates because they are of higher quality [27]. It is assumed that females prefer higher quality males for the direct benefits that these males provide, such as paternal care and indirect benefits such as "good gene" [4]. Though large body size has not been confirmed an indicator of good genes in burying beetles, larger individuals usually win the intrasexual contest [12] and acquire higher paternity in burying beetle species ( $N$. vespilloides: [29]). There are many conspecific and congeneric intruders even after the larvae have hatched [9], and the parents must guard the brood against them. Larger males usually win contests $[12,13]$, and pairs can guard their brood more effectively than a single female (Nicrophorus pustulatus: [17]). Intruders occasionally take over the owner's brood and kill all the larvae (Nicrophorus orbicollis, [30]). Thus, defence against intruders directly affects the reproductive success of the residents. Biparental care improves the protection against intruders provided to the brood by burying beetle parents (N. pustulatus: [31]). Trumbo [17] hypothesized that in burying beetles, the threat of infanticide is the primary reason for extended biparental care. In the field condition, sometimes reproductive pairs were determined without intrasexual contest [21]. In such situation, females must select whether they breed with the males presented now or wait for arriving another larger male. Although the relative importance of female choice is still unknown, females will have advantage on selecting larger males for pairs to prevent infanticide effectively. Females can acquire direct benefit by paternal care whether male body size is an indicator of genetic quality or not. In addition, it is said that parental investment is related to certainty of parentage [32], female may insure the paternity of larger male by the rejection of the copulation of smaller males to increase paternal care. Anyway, the effectiveness of mate rejection for females needs further investigation.

This study revealed that females rejected copulation with smaller males, smaller males attempted to copulate more frequently than larger males, and larger males attempted to copulate more frequently in the presence of other $N$. quadripunctatus males. Large-sized males have two advan- tages: they win contests between males and are preferred by females. Since the adult body size of burying beetles has important effects on reproductive success, the results suggest that the two above-mentioned factors prevent EPFs by smaller males.

\section{References}

[1] D. Lack, Ecological Adaptations for Breeding in Birds, Methuen, London, UK, 1968.

[2] D. F. Westneat and P. W. Sherman, "Density and extrapair fertilizations in birds: a comparative analysis," Behavioral Ecology and Sociobiology, vol. 41, no. 4, pp. 205-215, 1997.

[3] L. W. Simmons, Sperm Competition and Its Evolutionary Consequences in the Insects, Princeton University Press, Princeton, NJ, USA, 2001.

[4] M. Andersson, Sexual Selection, Princeton University Press, Princeton, NJ, USA, 1994.

[5] A.-K. Eggert and J. K. Müller, "Biparental care and social evolution in burying beetles: lessons from the larder," in The Evolution of Social Behavior in Insects and Arachnids, J. C. Choe and B. J. Crespi, Eds., pp. 216-236, Cambridge University Press, Cambridge, UK, 1997.

[6] M. P. Scott, "The ecology and behavior of burying beetles," Annual Review of Entomology, vol. 43, pp. 595-618, 1998.

[7] E. Pukowski, "Ökologische untersuchungen an Necrophorus F," Zeitschrift für Morphologie und Ökologie der Tiere, vol. 27, no. 3, pp. 518-586, 1933 (German).

[8] A.-K. Eggert and S. K. Sakaluk, "Benefits of communal breeding in burying beetles: a field experiment," Ecological Entomology, vol. 25, no. 3, pp. 262-266, 2000.

[9] S. T. Trumbo, "Interference competition among burying beetles (Silphidae, Nicrophorus)," Ecological Entomology, vol. 15, no. 3, pp. 347-355, 1990.

[10] S. T. Trumbo, "Monogamy to communal breeding: exploitation of a broad resource base by burying beetles (Nicrophorus)," Ecological Entomology, vol. 17, no. 3, pp. 289-298, 1992.

[11] S. T. Trumbo and A.-K. Eggert, "Beyond monogamy: territory quality influences sexual advertisement in male burying beetles," Animal Behaviour, vol. 48, no. 5, pp. 1043-1047, 1994.

[12] M. Otronen, "The effect of body size on the outcome of fights in burying beetles (Nicrophorus)," Annales Zoologici Fennici, vol. 25, no. 2, pp. 191-201, 1988.

[13] S. Suzuki, M. Nagano, and S. T. Trumbo, "Intrasexual competition and mating behavior in Ptomascopus morio (Coleoptera: Silphidae Nicrophorinae)," Journal of Insect Behavior, vol. 18, no. 2, pp. 233-242, 2005.

[14] I. C. Robertson, "Nest intrusions, infanticide, and parental care in the burying beetle, Nicrophorus orbicollis (Coleoptera: Silphidae)," Journal of Zoology, vol. 231, no. 4, pp. 583-593, 1993.

[15] M. P. Scott, "Brood guarding and the evolution of male parental care in burying beetles," Behavioral Ecology and Sociobiology, vol. 26, no. 1, pp. 31-39, 1990.

[16] S. T. Trumbo, "Interspecific competition, brood parasitism, and the evolution of biparental cooperation in burying beetles," Oikos, vol. 69, no. 2, pp. 241-249, 1994.

[17] S. T. Trumbo, "Defending young biparentally: female risktaking with and without a male in the burying beetle, Nicrophorus pustulatus," Behavioral Ecology and Sociobiology, vol. 61, no. 11, pp. 1717-1723, 2007. 
[18] J. K. Müller and A.-K. Eggert, "Paternity assurance by "helpful" males: adaptations to sperm competition in burying beetles," Behavioral Ecology and Sociobiology, vol. 24, no. 4, pp. 245-249, 1989.

[19] J. K. Müller, V. Braunisch, W. Hwang, and A.-K. Eggert, "Alternative tactics and individual reproductive success in natural associations of the burying beetle, Nicrophorus vespilloides," Behavioral Ecology, vol. 18, no. 1, pp. 196-203, 2007.

[20] J. K. Müller, A.-K. Eggert, and J. Dressel, "Intraspecific brood parasitism in the burying beetle, Necrophorus vespilloides (Coleoptera: Silphidae)," Animal Behaviour, vol. 40, no. 3, pp. 491-499, 1990.

[21] S. Suzuki, "Interference behavior of burying beetles on a carcass," New Entomologist, vol. 49, pp. 37-40, 2000 (Japanese).

[22] A.-K. Eggert and J. K. Müller, "Mating success of pheromoneemitting Necrophorus males: do attracted females discriminate against resource owners?" Behaviour, vol. 110, no. 1-4, pp. 248-257, 1989.

[23] J. Bartlett, "Male mating success and parental care in Nicrophorus vespilloides (Coleoptera: Silphidae)," Behavioral Ecology and Sociobiology, vol. 23, no. 5, pp. 297-303, 1988.

[24] R. Montgomerie and R. Thornhill, "Fertility advertisement in birds: a means of inciting male-male competition," Ethology, vol. 81, pp. 209-220, 1989.

[25] A. Berglund, A. Bisazza, and A. Pilastro, "Armaments and ornaments: an evolutionary explanation of traits of dual utility," Biological Journal of the Linnean Society, vol. 58, no. 4, pp. 385-399, 1996.

[26] B. B. M. Wong, "Superior fighters make mediocre fathers in the Pacific blue-eye fish," Animal Behaviour, vol. 67, no. 3, pp. 583-590, 2004.

[27] A. Qvarnström and E. Forsgren, "Should females prefer dominant males?" Trends in Ecology \& Evolution, vol. 13, no. 12, pp. 498-501, 1998.

[28] S. K. Sakaluk and J. K. Müller, "Risk of sperm competition mediates copulation duration, but not paternity, of male burying beetles," Journal of Insect Behavior, vol. 21, no. 3, pp. 153-163, 2008.

[29] M. P. Scott and S. M. Williams, "Comparative reproductive success of communally breeding burying beetles as assessed by PCR with randomly amplified polymorphic DNA," Proceedings of the National Academy of Sciences of the United States of America, vol. 90, no. 6, pp. 2242-2245, 1993.

[30] S. T. Trumbo, "Reproductive benefits of infanticide in a biparental burying beetle Nicrophorus orbicollis," Behavioral Ecology and Sociobiology, vol. 27, no. 4, pp. 269-273, 1990.

[31] S. T. Trumbo, "Infanticide, sexual selection and task specialization in a biparental burying beetle," Animal Behaviour, vol. 72, no. 5, pp. 1159-1167, 2006.

[32] B. C. Sheldon, "Relating paternity to paternal care," Philosophical Transactions of the Royal Society B, vol. 357, no. 1419, pp. 341-350, 2002. 

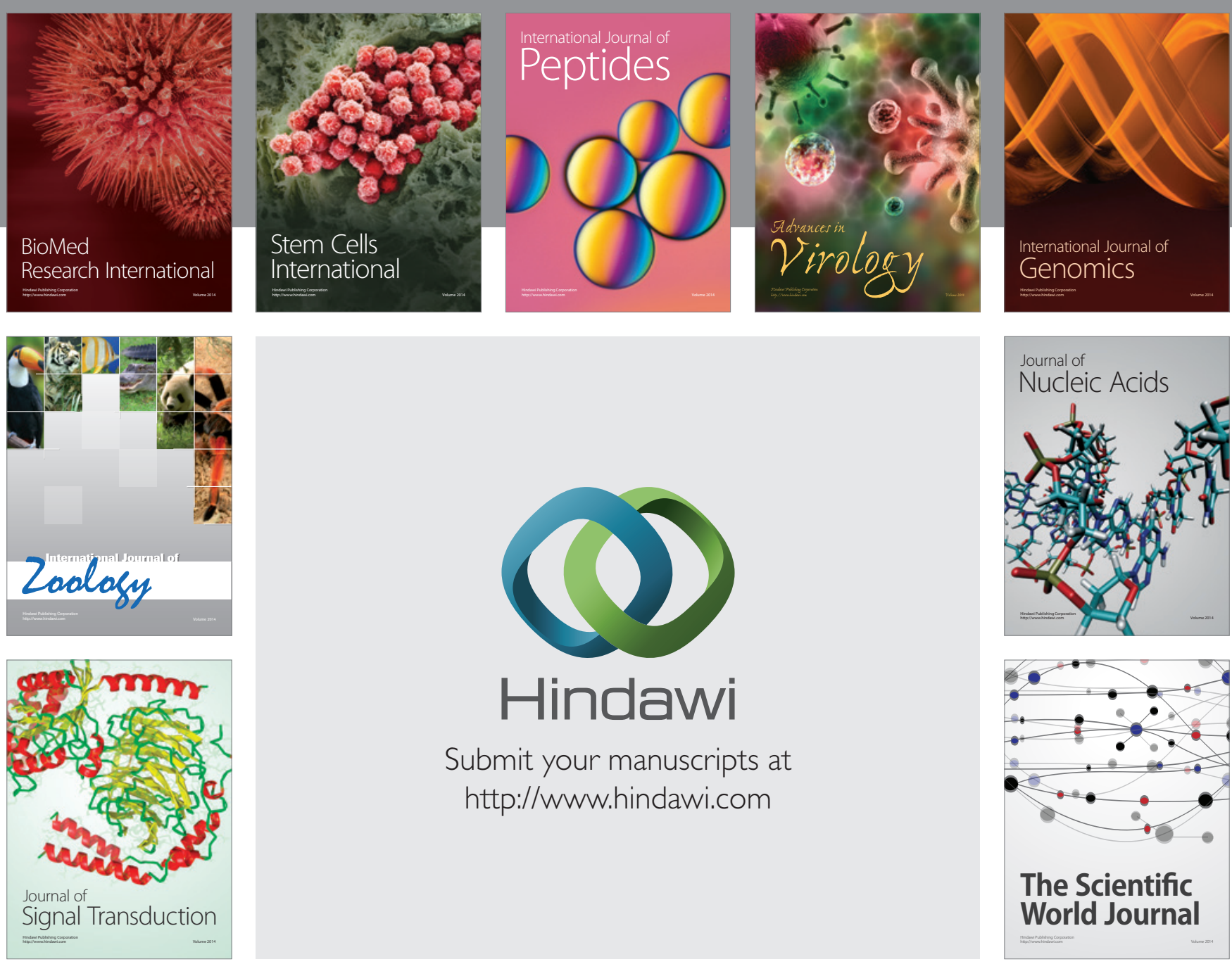

Submit your manuscripts at

http://www.hindawi.com
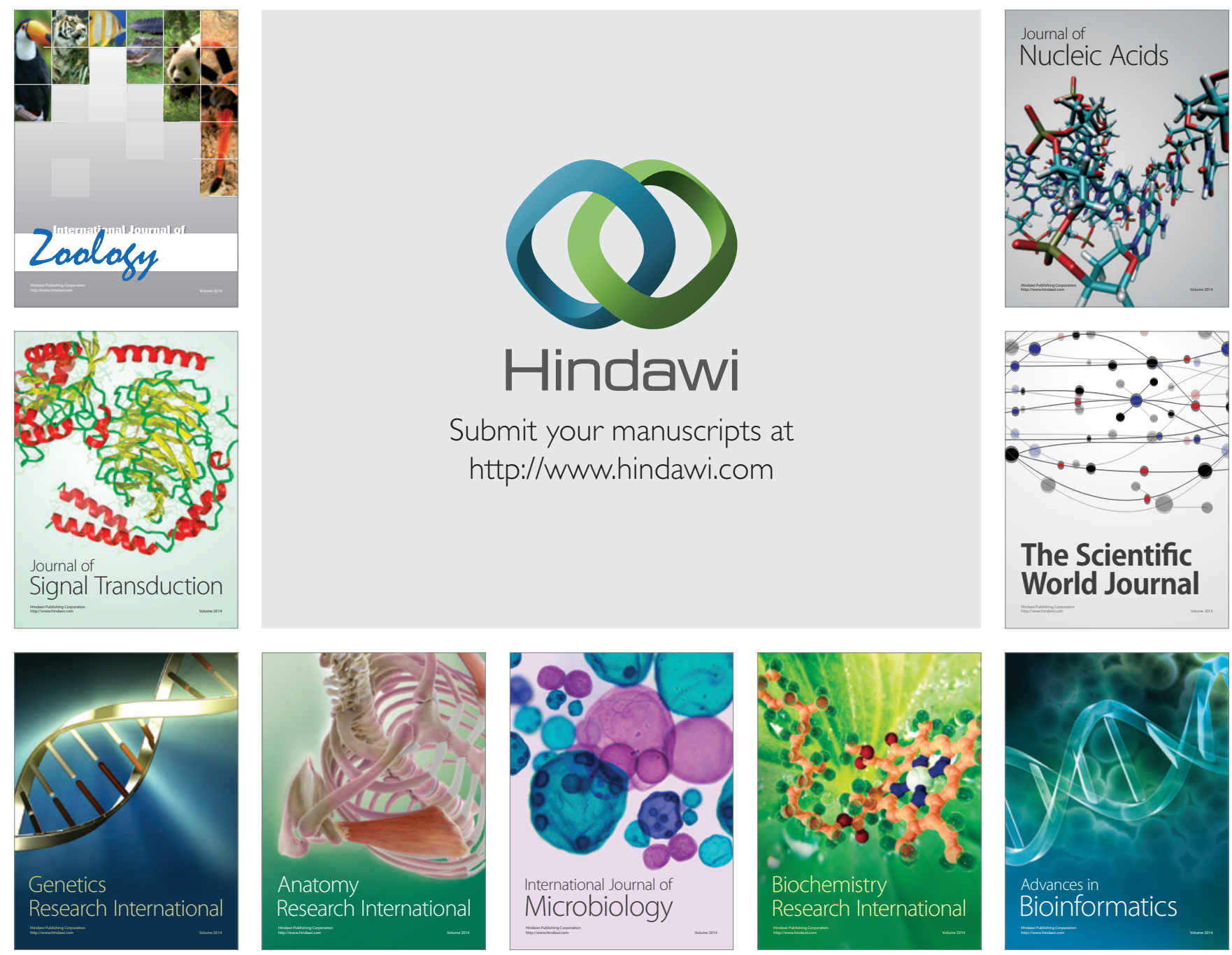

The Scientific World Journal
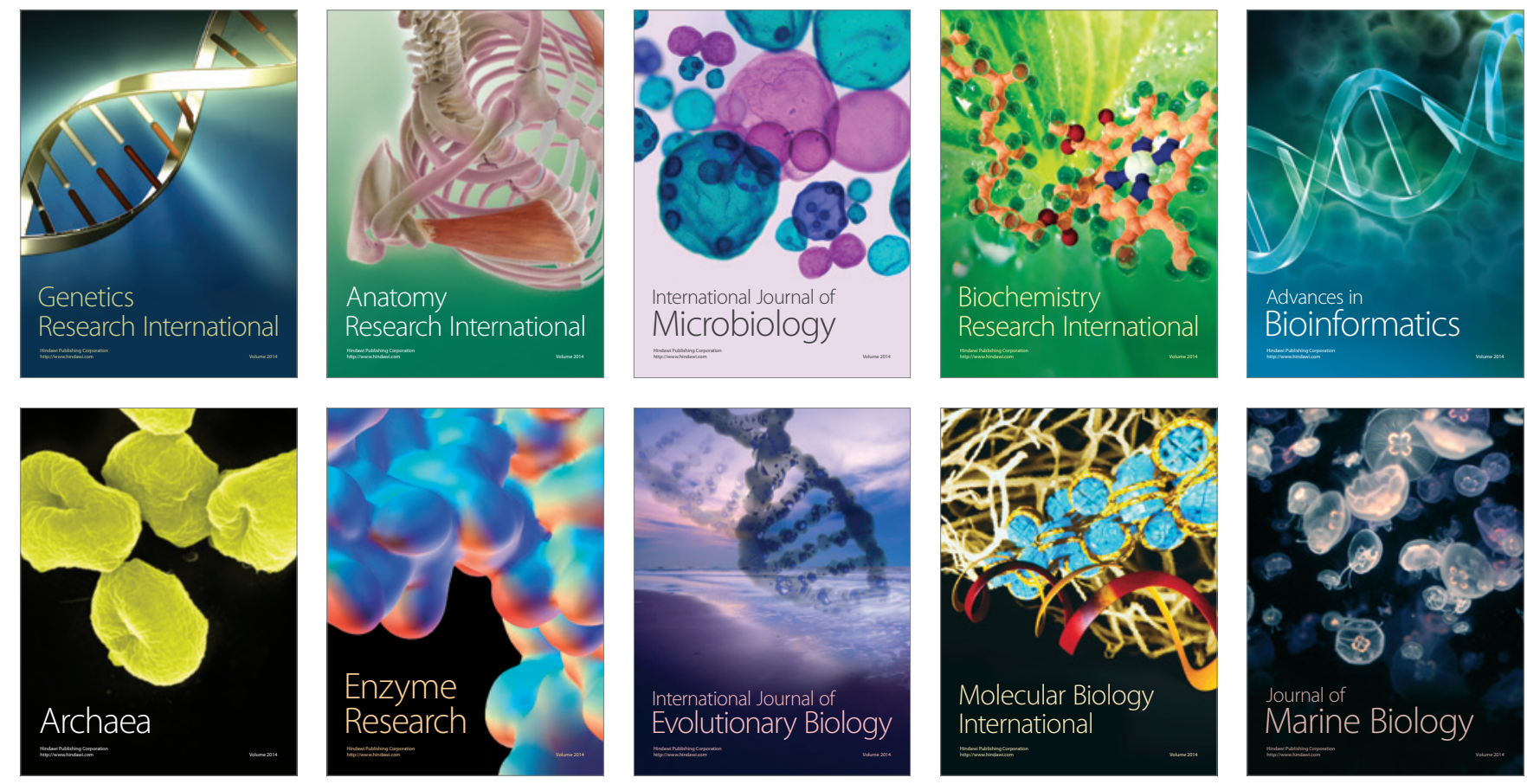